Check for updates

Cite this: RSC Adv., 2018, 8, 38370

\title{
Multiple halide anion doped layered bismuth terephthalate with excellent photocatalysis for pollutant removal $\dagger$
}

\author{
Xinyun Zhao, (D) *a Huihui Chen, ${ }^{a} \mathrm{Xi} C h e n,{ }^{a}$ Juncheng Hu, (D) a Tsunghsueh Wu, ${ }^{\mathrm{b}}$ \\ Lamei $\mathrm{Wu}^{* a}$ and Mei Li ${ }^{\mathrm{a}}$
}

In order to improve the photocatalytic activities of layered MOF bismuth terephthalate, five multiple halide anion doped bismuth terephthalate composites were prepared by doping three or four halide anions each with a molar ratio of $\mathrm{X}^{-} / \mathrm{Bi}^{3+}\left(\mathrm{X}=\mathrm{F}^{-}, \mathrm{Cl}^{-}, \mathrm{Br}^{-}, \mathrm{I}^{-}\right)$at 0.25 . The $\mathrm{F}^{-}, \mathrm{Cl}^{-}, \mathrm{Br}^{-}$codoped and $\mathrm{F}^{-}, \mathrm{Cl}^{-}, \mathrm{Br}^{-}, \mathrm{I}^{-}$ codoped bismuth terephthalate composites exhibit 41 and 35 times higher photocatalytic degradation activities for RhB, 7 and 6 times higher for salicylic acid than that of bismuth terephthalate. Excellent photocatalytic activities could be ascribed to the microstructure of multiple halide anion doped composites, large specific BET surface area and effective separation of photogenerated electron-hole pairs. Incorporating multiple negatively charged $\mathrm{F}^{-}, \mathrm{Cl}^{-}, \mathrm{Br}^{-}, \mathrm{I}^{-}$into layered bismuth terephthalate can improve the photocatalytic and electrochemical activities of bismuth terephthalate. The composites presented in this study can be potentially applied in photocatalysis and electrochemical fields as multifunctional materials.

Received 14th October 2018 Accepted 8th November 2018

DOI: $10.1039 / \mathrm{c} 8 \mathrm{ra0} 8493 a$

rsc.li/rsc-advances solving current energy related challenges. As an environmentally benign element, ${ }^{6}$ bismuth-based MOFs constructed from carboxylates or analogs have been reported to exhibit good photocatalytic activities. ${ }^{16}$ But to date, bismuth terephthalate has been overlooked even though the catalyst consisting of bismuth terephthalate $\mathrm{TiO}_{2} / \mathrm{Bi}_{2}(\mathrm{BDC})_{3} / \mathrm{BiOCl}$ has been demonstrated to be effective in pollutant degradation under visible light irradiation. ${ }^{17} \mathrm{Bi}_{2}(\mathrm{BDC})_{3}$ itself has no apparent photodegradation activity. The layered microstructure of bismuth terephthalate was envisioned as a potential candidate for the construction of multifunctional materials. ${ }^{\mathbf{1 8}}$ For example, bismuth terephthalate consists of $\left[\mathrm{Bi}_{2} \mathrm{O}_{2}\right]$ slabs, which include distorted $\mathrm{Bi}-\mathrm{O}$ polyhedra. These $\left[\mathrm{Bi}_{2} \mathrm{O}_{2}\right]$ sheets are connected via 1,4-benzenedicarboxylic acid ligand along the $z$-direction to create the pillared 3D structure (Fig. S1a $\dagger$ ). The continuous chains of Bi-O bridges allow effective charge mobility within the crystal of bismuth terephthalate. ${ }^{1}$ More interestingly, its layered microstructure is similar to that of inorganic semiconductors BiOX ( $\mathrm{X}=\mathrm{Cl}, \mathrm{Br}, \mathrm{I})$, which have been applied widely in photocatalysis and chemical conversion. ${ }^{19-22}$ The microstructure of BiOCl was depicted in Fig. S1b. $\dagger$ It has been clearly shown that combination of multiple species of halide anions $\left(\mathrm{Cl}^{-}, \mathrm{Br}^{-}\right)$, $\left(\mathrm{Br}^{-}, \mathrm{I}^{-}\right),\left(\mathrm{Cl}^{-}, \mathrm{I}^{-}\right)$and $\left(\mathrm{Cl}^{-}, \mathrm{Br}^{-}\right.$and $\left.\mathrm{I}^{-}\right)$within BiOX framework significantly enhances the photocatalytic activity. ${ }^{23-29}$ Because halogens can induce efficient charge separation and transfer. ${ }^{28,30}$ Our previous studies have improved photocatalytic performance for bismuth terephthalate by changing the halide dopants, doped molar ratios of $\mathrm{X}^{-} / \mathrm{Bi}^{3+}$ were optimized from 0.25 to 0.75 and found that molar ratio of each halide anion at 
0.25 was an optimal composition concentration. ${ }^{31-33}$ But a systematical study bismuth terephthalate is still needed to elucidate the effect of multiple halide dopants with the same molar ratios on bismuth terephthalate.

Herein, this study was designed to investigate the effect of incorporating multiple species of halide anions from the combination of $\mathrm{F}^{-}, \mathrm{Cl}^{-}, \mathrm{Br}^{-}$and $\mathrm{I}^{-}$on photocatalytic activities of bismuth terephthalate. Five composites i.e. T1 (containing $\mathrm{F}^{-}, \mathrm{Cl}^{-}, \mathrm{Br}^{-}$), T2 (containing $\mathrm{F}^{-}, \mathrm{Cl}^{-}, \mathrm{I}^{-}$), T3 (containing $\mathrm{F}^{-}$, $\mathrm{Br}^{-}, \mathrm{I}^{-}$), T4 (containing $\mathrm{Cl}^{-}, \mathrm{Br}^{-}, \mathrm{I}^{-}$) and $\mathrm{T} 5$ (containing $\mathrm{F}^{-}, \mathrm{Cl}^{-}$, $\mathrm{Br}^{-}, \mathrm{I}^{-}$) were prepared in $N, N$-dimethylformamide (DMF) with a fixed molar ratio of $\mathrm{X}^{-} / \mathrm{Bi}^{3+}$ at 0.25 . Their photocatalytic activities were studied on the degradation of RhB and salicylic acid. Active species trapping experiments were also performed on RhB degradation under visible light irradiation over T1 catalyst.

\section{Experimental section}

\section{Preparation of composites}

For each composite sample prepared in this study, fixed amount of $\mathrm{Bi}\left(\mathrm{NO}_{3}\right)_{3} \cdot 5 \mathrm{H}_{2} \mathrm{O}, 1.33 \mathrm{mmol}(0.645 \mathrm{~g})$, was used, the molar ratio of each halide anion from $\mathrm{NaF}, \mathrm{NaCl}, \mathrm{NaBr}$ and $\mathrm{NaI}$ relative to $\mathrm{Bi}\left(\mathrm{NO}_{3}\right)_{3}$ was kept at $0.25(0.3325 \mathrm{mmol})$ and $2 \mathrm{mmol}(0.332 \mathrm{~g})$ of terephthalic acid was used. The detailed preparation process of the T1 composite was as followed. First, terephthalic acid was dissolved in $15 \mathrm{~mL}$ of DMF by stirring while $\mathrm{Bi}\left(\mathrm{NO}_{3}\right)_{3} \cdot 5 \mathrm{H}_{2} \mathrm{O}$ was dissolved separately in $20 \mathrm{~mL}$ of DMF by sonication. Three species of sodium halides $\mathrm{NaF}, \mathrm{NaCl}$, and $\mathrm{NaBr}$ (each 0.3325 mmol) were added to the terephthalic acid solution and stirred for 10 minutes. Then the solution of $\mathrm{Bi}\left(\mathrm{NO}_{3}\right)_{3}$ was added dropwise into the halide containing terephthalic acid solution with vigorous magnetic stirring. Finally, the resulted mixture was transferred to a $100 \mathrm{~mL}$ of Teflon-lined stainless steel autoclave and heated at $120{ }^{\circ} \mathrm{C}$ for $24 \mathrm{~h}$ without stirring. The mixture was allowed to cool to room temperature. The precipitate was collected by filtration, washed with ethanol and deionized water and dried at $100{ }^{\circ} \mathrm{C}$ overnight. Similarly, composites T2 ( NaF, NaCl, and NaI as halide source), T3 (NaF, $\mathrm{NaBr}$, and $\mathrm{NaI}$ as halide source), $\mathrm{T} 4$ ( $\mathrm{NaCl}, \mathrm{NaBr}$ and $\mathrm{NaI}$ as halide source) and $\mathrm{T} 5$ ( $\mathrm{NaF}, \mathrm{NaCl}, \mathrm{NaBr}$, and $\mathrm{NaI}$ as halide source) were prepared by using the same procedure.

\section{Characterization of multiple halide doped composites}

Powder X-ray diffraction (XRD) patterns of as-prepared samples were obtained on Bruker D8 Advance using $\mathrm{Cu} \mathrm{K} \alpha$ radiation $(\lambda=$ $0.15404 \mathrm{~nm}$ ) with $2 \theta$ ranging from $10^{\circ}$ to $80^{\circ}$ at a scanning rate of $0.05^{\circ} \mathrm{s}^{-1}$. FT-IR spectra were tested on a Nicolet NEXUS 4700 spectrometer. The morphologies of samples and the average atomic percentage were obtained on an SU8010 field emission scanning electron microscope equipped with energy dispersive X-ray (EDX) analysis. UV-Vis diffuse reflectance spectroscopy (DRS) was performed on a Shimadzu UV-2550 spectrophotometer, which was equipped with an integrating sphere. Photocurrent test and electrochemical impedance spectroscopy (EIS) was performed on CHI760E electrochemical station. The frequency range of EIS was 1-100 $\mathrm{kHz}$ with the initial electric voltage at $1.6 \mathrm{~V}$ and the amplitude at $0.005 \mathrm{~V}$. The BrunauerEmmett-Teller (BET) specific surface areas of composites were determined by $\mathrm{N}_{2}$ adsorption-desorption isotherms on a Micromeritics ASAP 2020 gas adsorption apparatus. Pore-size distributions were obtained from the adsorption isotherms by using the Barrett-Joyner-Halenda $(\mathrm{BJH})$ model for data fitting. Photoluminescence (PL) spectra of as-prepared samples was obtained from FL-7000 spectrophotometer.

\section{Evaluation of photocatalytic activities}

In each experiment, the composite catalyst $(50 \mathrm{mg})$ was dispersed in $50 \mathrm{~mL}$ of $\mathrm{RhB}\left(20 \mathrm{mg} \mathrm{L}^{-1}\right)$ or salicylic acid aqueous solution $\left(20 \mathrm{mg} \mathrm{L}^{-1}\right)$ by sonication at a constant temperature of $25{ }^{\circ} \mathrm{C}$ in a water bath for $10 \mathrm{~min}$. Then the suspension was magnetically stirred for $2 \mathrm{~h}$ in the dark to reach the adsorptiondesorption equilibrium. Subsequently, the RhB mixture was exposed to visible light (350 W xenon lamp with $420 \mathrm{~nm}$ cutoff filter) while the salicylic acid mixture was exposed to UV light (350 W xenon lamp with $365 \mathrm{~nm}$ cutoff filter) with a constant magnetically stirring speed. The photolysis was performed at $25{ }^{\circ} \mathrm{C}$. The progress of photocatalytic degradation was monitored by taking $3 \mathrm{~mL}$ of reaction suspension at specified time intervals. This suspension was centrifuged and then filtered through a Millipore filter to remove the residue photocatalysts. The concentration was analyzed from the recorded absorbance at $553 \mathrm{~nm}$ and $296 \mathrm{~nm}$ for RhB and salicylic acid, respectively.

\section{Active species trapping experiments over T1 catalyst}

Excess benzoquinone (BQ), ethylenediaminetetraacetic acid disodium salt (EDTA) and isopropanol (IPA) with a final concentration of $1 \mathrm{mmol} \mathrm{L}^{-1}$ were added into $50 \mathrm{~mL}$ of $\mathrm{RhB}$ (20 $\mathrm{mg} \mathrm{L}^{-1}$ ) aqueous solution over $\mathrm{T} 1$ catalyst for trapping superoxide radical $\left(\cdot \mathrm{O}^{2-}\right),{ }^{34}$ holes $\left(\mathrm{h}^{+}\right),{ }^{25}$ and hydroxyl radical $(\cdot \mathrm{OH}) .{ }^{35}$ The procedure of photodegradation was similar to that of RhB photodegradation over $\mathrm{T} 1$ catalyst under visible light irradiation.

\section{Electrochemical measurements}

The transient photocurrent measurements and electrochemical impedance spectroscopy (EIS) were carried out on CHI760E electrochemical station in a standard three-electrode system, with the catalyst-coated FTO glass as the working electrode, a Pt foil as a counter electrode, and a saturated $\mathrm{Ag}-\mathrm{AgCl}$ electrode as the reference electrode. The light source was from a $3 \mathrm{~W} 365 \mathrm{~nm}$ LED UV lamp. The electrolyte was $0.4 \mathrm{M} \mathrm{Na}_{2} \mathrm{SO}_{4}$ solution. Multiple $100 \mathrm{~s}$ switch on - switch off cycles without bias voltages were used to perform for photocurrent tests. ${ }^{36}$

\section{Results and discussion}

\section{Composition analysis and morphologies}

IR spectra from all five multiple halide anions doped bismuth terephthalate composites T1-T5, terephthalic acid, bismuth terephthalate (BiBDC) are shown in Fig. 1. Detailed spectra of each sample are shown in Fig. S2-S8 (in ESI $\dagger$ ). Characteristic 


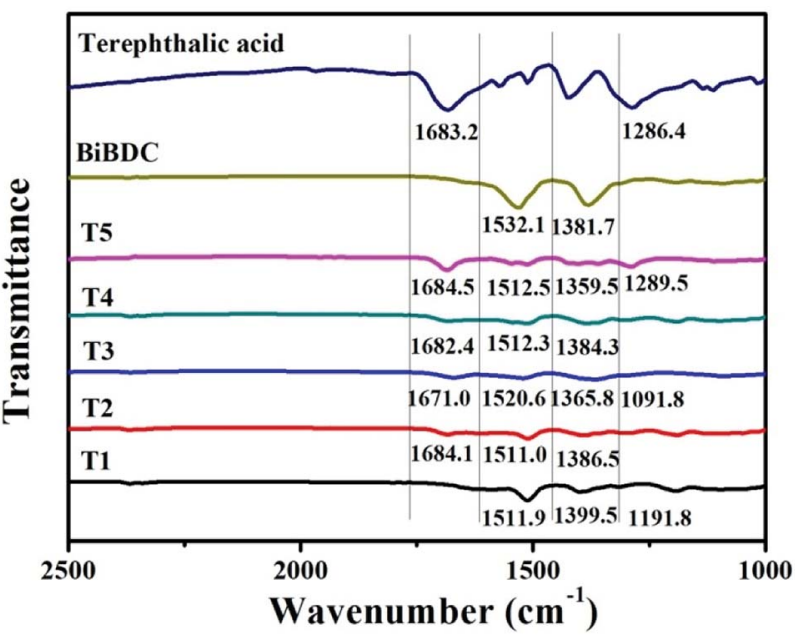

Fig. 1 IR spectra of T1 to T5, terephthalic acid and BiBDC.

peaks of carboxyl groups from terephthalic acid are identified at $1683.2 \mathrm{~cm}^{-1}(\mathrm{C}=\mathrm{O})$ and $1286.4 \mathrm{~cm}^{-1}(\mathrm{C}-\mathrm{O})$, consistent with the reported data in the literature. ${ }^{37}$ After the carboxyl groups of terephthalic acid coordinate with $\mathrm{Bi}^{3+}$ to form BiBDC, these peaks disappear and two new characteristic peaks (1532.1 and $1381.7 \mathrm{~cm}^{-1}$ ) emerge. All prepared multiple halide anions doped bismuth terephthalate composites have absorption peaks at 1511.1-1520.6 $\mathrm{cm}^{-1}$ and $1365.8-1399.5 \mathrm{~cm}^{-1}$, indicating the presence of complexation between carboxyl groups and $\mathrm{Bi}^{3+}$. T2, T3, T4 and T5 composites have additional absorption peaks at 1684.1, 1671.0, 1682.4 and $1684.5 \mathrm{~cm}^{-1}$, respectively. This suggests that carboxyl groups of terephthalic acid within T2-T5 are partially coordinated to $\mathrm{Bi}^{3+}$. Doped multiple halide anions can affect the coordination of $\mathrm{Bi}^{3+}$. Surprisingly, two carboxyl groups within the composite T1 (containing $\mathrm{F}^{-}, \mathrm{Cl}^{-}, \mathrm{Br}^{-}$) are completely coordinated to $\mathrm{Bi}^{3+}$. This can be confirmed by disappearing of two peaks at $1683.2 \mathrm{~cm}^{-1}$ and $1286.4 \mathrm{~cm}^{-1}$ with two new absorption peaks appearing at $1511.9 \mathrm{~cm}^{-1}$ and $1399.5 \mathrm{~cm}^{-1}$. It is noteworthy that doped $\mathrm{I}^{-}$anions for $\mathrm{T} 5$ composite (containing $\mathrm{F}^{-}, \mathrm{Cl}^{-}, \mathrm{Br}^{-}$and $\mathrm{I}^{-}$) enormously change the coordination of $\mathrm{Bi}^{3+}$ with carboxyl groups.

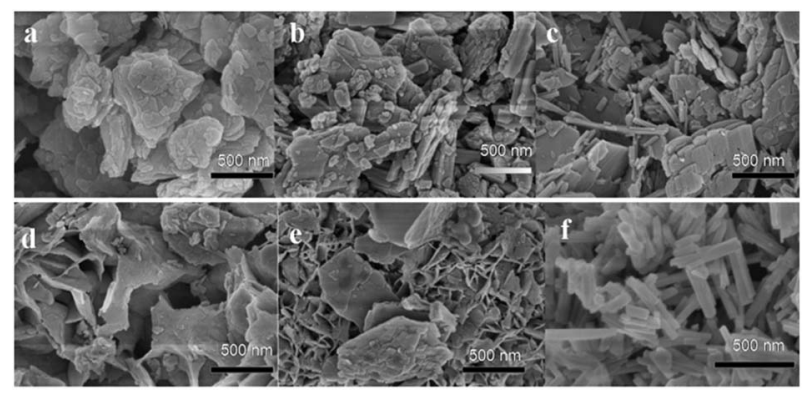

Fig. 2 Representative SEM images of the obtained samples T1 (a), T2 (b), T3 (c), T4 (d), T5 (e) and BiBDC (f).

Normal XRD patterns (10 to 80 degree) and low angle XRD pattern (from 0 to 5 degree) of as-prepared multiple halide anions doped bismuth terephthalate can be seen in Fig. S9 and S10 (in ESI $\dagger$ ). T1 composite shows relatively higher crystallinity than those of other multiple halide anions doped bismuth terephthalate. The result from low angle XRD patterns show that MOF scaffold was not changed after halide anions doped.

The real molar ratios of halide anions $\mathrm{X}^{-}$to $\mathrm{Bi}^{3+}$ within asprepared samples can be determined by the EDS patterns. Each kind of halide anions was used for the preparation of these composites with the molar ratio of $\mathrm{X}^{-} / \mathrm{Bi}^{3+}$ at 0.25 . Experimentally determined atomic ratios of doped halide anions in the composites do not equate to the ratios from the results of EDS (Table 1 and Fig. S11-S15 in ESI $\dagger$ ). Overall, all halide anions can be doped into bismuth terephthalate. For $\mathrm{F}^{-}, \mathrm{Cl}^{-}$and $\mathrm{Br}^{-}$, they are easy to be doped owing to their smaller ionic radius. Moreover, bromide anions were preferentially doped into the composite over all other halide anions. And for $\mathrm{I}^{-}$, it is the least favourable in doping, attributing to its large ionic radius. For T1 and $\mathrm{T} 5$ composites, a little difference between them is the presence of a small amount of $\mathrm{I}^{-}$within $\mathrm{T} 5$.

The morphologies of as-prepared samples were characterized by SEM images. Fig. 2 shows the SEM images of T1 to T5 and BiBDC. The study shows a transformation of rod-like morphology in BiBDC to lamellar structures upon doping with multiple halide anions. T1 presents a well-defined lamellar microstructure while $\mathrm{T} 2$ and $\mathrm{T} 3$ composites have both rod-like

Table 1 Degradation rate constant $k\left(\mathrm{~min}^{-1}\right)$ for $\mathrm{RhB}, k\left(\mathrm{~h}^{-1}\right)$ for salicylic acid and specific BET surface area over multiple halide doped composites

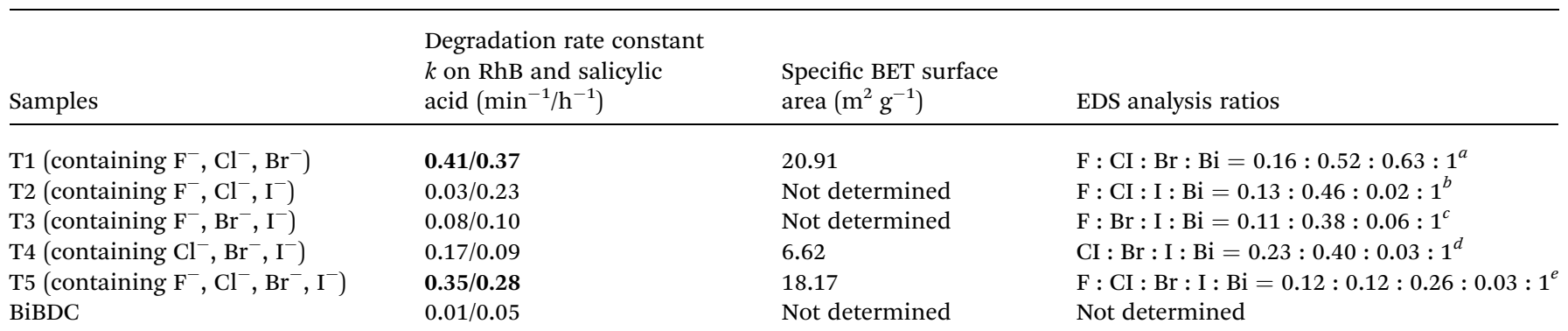

${ }^{a}$ Prepared ratios: $\mathrm{F}: \mathrm{CI}: \mathrm{Br}: \mathrm{Bi}=0.25: 0.25: 0.25: 1 .{ }^{b}$ Prepared ratios: $\mathrm{F}: \mathrm{CI}: \mathrm{I}: \mathrm{Bi}=0.25: 0.25: 0.25: 1 .{ }^{c}$ Prepared ratios: $\mathrm{F}: \mathrm{Br}: \mathrm{I}: \mathrm{Bi}=$ $0.25: 0.25: 0.25: 1 .{ }^{d}$ Prepared ratios: $\mathrm{CI}: \mathrm{Br}: \mathrm{I}: \mathrm{Bi}=0.25: 0.25: 0.25: 1 .{ }^{e}$ Prepared ratios: $\mathrm{F}: \mathrm{CI}: \mathrm{Br}: \mathrm{I}: \mathrm{Bi}=0.25: 0.25: 0.25: 1$. 

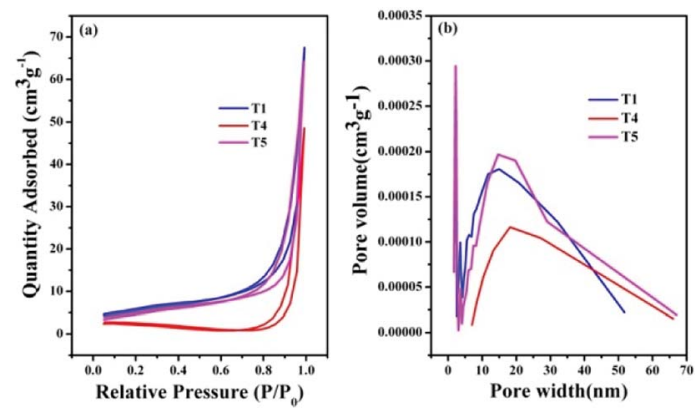

Fig. 3 Nitrogen adsorption-desorption isotherms and pore size distribution of $\mathrm{T} 1, \mathrm{~T} 4$ and $\mathrm{T} 5$.

and lamellar structures. The lamellar microstructure of $\mathrm{T} 4$ and T5 composites were irregular in shape. Lamellar aligned morphology of T1 may enhance the activity of photocatalysts according to the knowledge from previous report. ${ }^{20}$

\section{Surface properties of the as-prepared composites}

$\mathrm{N}_{2}$ adsorption-desorption isotherms and broad pore size distributions of T1, T4 and T5 are shown in Fig. 3a and b. Their specific Brunauer-Emmett-Teller (BET) surface areas have been found to be $20.91,6.62$, and $18.17 \mathrm{~m}^{2} \mathrm{~g}^{-1}$ respectively. A type IV isotherm with a type $\mathrm{H} 3$ hysteresis loop in each sample can be found according to the IUPAC classification. T1 shows the largest BET surface area among all due to its well-defined lamellar microstructure, ideal for adsorption of organic pollutants and light absorption. Unlike T1, T5 contains a small amount of iodide ions, resulting a decreased specific BET surface area $\left(18.17 \mathrm{~m}^{2} \mathrm{~g}^{-1}\right)$.

\section{Optical and photoelectric properties of as-prepared composites}

UV-Vis diffuse reflectance spectroscopy (DRS) are used to investigate the optical properties of the catalysts. The results are presented in Fig. 4a. The absorption edges of as-prepared samples locate at about $390 \mathrm{~nm}$ in the UV region; thus, they are UV light-responsive catalysts. In order to investigate the characteristics of photoinduced charge separation for all five composites, photoluminescence (PL) emission and transient photocurrent response were measured. Fig. $4 \mathrm{~b}$ shows the PL spectra of the as-prepared composites at $25{ }^{\circ} \mathrm{C}$ with an excitation wavelength of $314 \mathrm{~nm}$. As it is well known, the luminescence occurs via the recombination of electrons in the conduction band and holes in the valence band. A sample with low photoluminescence intensity has the low recombination rate of the electrons and holes, an important indicator for strong photocatalytic activity. ${ }^{38}$ As shown in Fig. 4b, the PL spectra of T1 composite displays lowest PL intensity among five multiple halide anions doped composites, clearly revealing its superior separation efficiency of photogenerated electron-hole pairs. On the other hand, the photoelectric properties of $\mathrm{T} 1$ to T5 were evaluated with a three-electrode system. Fig. 4c shows transient photocurrent responses of $\mathrm{T} 1$ to $\mathrm{T} 5$ and BiBDC under intermittent UV light illumination from a $3 \mathrm{~W}$ LED lamp. T1 and
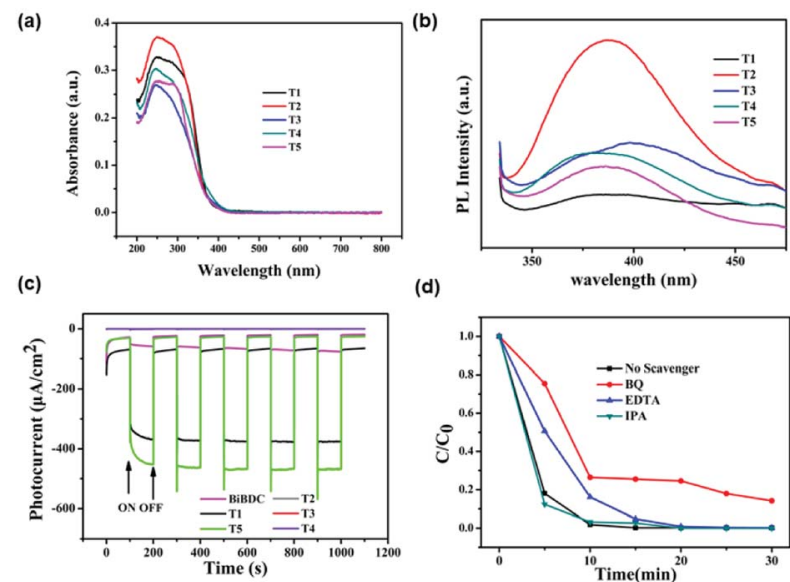

(d)

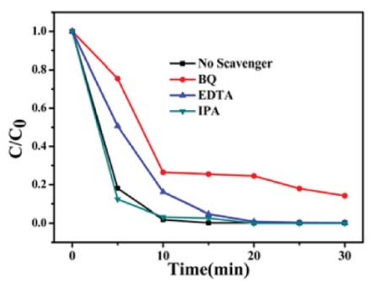

Fig. 4 UV-Vis DRS (a) and the photoluminescence (PL) spectra (b) of the as-prepared samples T1-T5; transient photocurrent response of T1-T5 and BiBDC under UV light irradiation (c); visible light degradation of RhB over catalyst T1 in the presence or absence of scavengers (d).

T5 electrodes both exhibit stronger photoelectric current than BiBDC, supporting their higher efficiency in electron-hole pair separation under UV light irradiation than other composites.

\section{Electrochemical impedance spectroscopy (EIS) of T1 and T5 electrodes}

T1 and T5 composites have relatively good photocatalytic activities, which could be attributed to the enhanced charge transfer by doping bismuth terephthalate with multiple halide anions. Electrochemical impedance spectroscopy (EIS) of T1 and $\mathrm{T} 5$ electrodes were performed under a frequency range of 1$100 \mathrm{kHz}$ and the Nyquist plots of both electrodes are shown in Fig. 5. The diameter of semicircle in Nyquist plot quantifies the charge transfer resistance.$^{39}$ From Nyquist plots, T1 composite has lower charge transfer resistance than $\mathrm{T}$, suggesting that the charge-transfer resistance was increased in the presence of iodide anion in the T5 composite owing to larger diameter of semicircle.

\section{Photodegradation activities over multiple halide anions doped composites}

Rhodamine (RhB) and salicylic acid with $20 \mathrm{mg} \mathrm{L}^{-1}$ were used as model pollutants to evaluate photodegradation activities over as-prepared multiple halide anions doped bismuth terephthalate composites. Because all catalysts are UV light

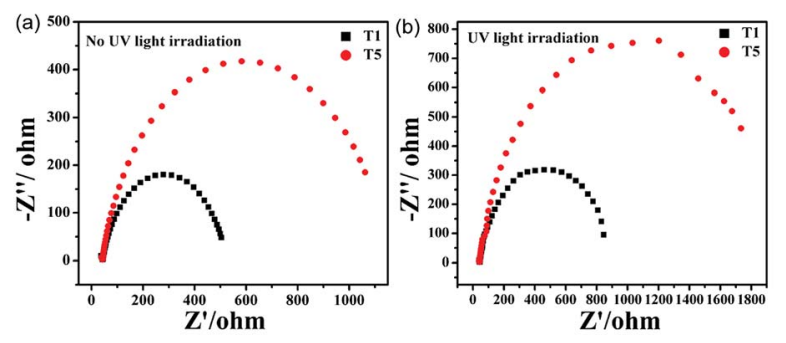

Fig. 5 EIS Nyquist plots of T1 and T5 electrode without UV light irradiation (a) and with UV light irradiation (b). 

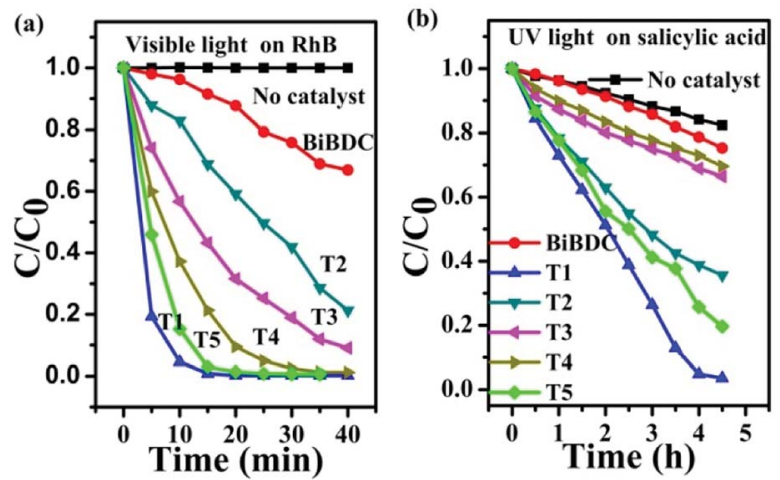

Fig. 6 Degradation of $20 \mathrm{mg} \mathrm{L}^{-1} \mathrm{RhB}$ under visible light irradiation (a) and $20 \mathrm{mg} \mathrm{L}^{-1}$ salicylic acid under UV light irradiation (b) over multiple halide anions doped composites.

response, colorless salicylic acid can be degradated only under UV light irradiation. Degradation of RhB under visible light and salicylic acid under UV light was monitored respectively. Concentration variations $\left(C / C_{0}\right)$ for $\mathrm{RhB}$ and salicylic acid with the radiation time are shown in Fig. 6. The apparent rate constants were calculated based on the pseudo-first order kinetics by plotting $\ln \left(C_{0} / C\right)$ as a function of time, where the $C_{0}$ and $C$ are the concentrations $\left(\mathrm{mg} \mathrm{L}^{-1}\right)$ at time zero and at a given time $t$ under light irradiation respectively and $k$ is the first order degradation rate constant $\left(\mathrm{min}^{-1}\right.$ for $\mathrm{RhB}$ and $\mathrm{h}^{-1}$ for salicylic acid). The results are summarized in Table 1. For RhB, degradation of $\mathrm{RhB}$ itself under visible light is negligible. All five as-prepared composites exhibit good visible light degradation activities than BiBDC. T1 composite (containing $\mathrm{F}^{-}, \mathrm{Cl}^{-}$and $\mathrm{Br}^{-}$) exhibits the best degradation efficiency with the rate constant $0.41 \mathrm{~min}^{-1}$ (Table 1). It is 41 times higher than that of bismuth terephthalate (BiBDC, $0.01 \mathrm{~min}^{-1}$ ). $\mathrm{RhB}$ with a controlled concentration of $20 \mathrm{mg} \mathrm{L}^{-1}$ were completely decomposed by T1 within 10 minutes under visible light irradiation. Photocatalytic activity of composite T5 is 35 times higher than that of BiBDC. Comparing with T1, the decrease of degradation activity for $\mathrm{T} 5$ can be related to its smaller specific BET surface area, irregular morphology and the presence of doped iodide anions.

Degradation of colorless salicylic acid by all five composites is much slower process than degradation of RhB. Fig. $6 \mathrm{~b}$ and Table 1 show T1 and T5 composites exhibit photocatalytic activities with the reaction rate constant of 0.37 and $0.28 \mathrm{~h}^{-1}$, respectively, better than $\mathrm{T} 2, \mathrm{~T} 3$ and $\mathrm{T} 4$. Quantitatively, $\mathrm{T} 1$ exhibits 7 times higher photocatalytic degradation of salicylic acid than BiBDC, while T5 exhibits only 6 times higher. Compared with our reported results previously about the photocatalytic degradation of RhB under visible light irradiation, single $\mathrm{Br}^{-}$anion doped bismuth terephthalate from the similar preparation method exhibits 13 times higher degradation activity than BiBDC. ${ }^{31}$ Furthermore, binary $\mathrm{F}^{-}$and $\mathrm{I}^{-}$anions codoped bismuth terephthalate presents 26 times higher RhB degradation activity than bismuth terephthalate in the same conditions. ${ }^{32}$ Apparently, doping from multiple halide anions greatly enhances photodegradation activity of RhB to 41 and 35 times higher from $\mathrm{T} 1$ (containing $\mathrm{F}^{-}, \mathrm{Cl}^{-}, \mathrm{Br}^{-}$) and $\mathrm{T} 5$ (containing $\mathrm{F}^{-}, \mathrm{Cl}^{-}, \mathrm{Br}^{-}, \mathrm{I}^{-}$) respectively. It is also clear that degradation of $\mathrm{RhB}$ and salicylic acid was impeded by the presence of doped iodide anions owing to the decrease of BET specific surface area.

\section{Possible visible light photodegradation process on $\mathrm{RhB}$}

To elucidate photodegradation process of $\mathrm{RhB}$ over multiple halide doped bismuth terephthalate composites under visible light irradiation, scavenging experiments for common active species such as hydroxyl radical $(\cdot \mathrm{OH})$, superoxide radical $\left(\cdot \mathrm{O}^{2-}\right)$, electron $\left(\mathrm{e}^{-}\right)$and active holes $\left(\mathrm{h}^{+}\right)$in the photochemical process were conducted. In the experiment, the scavenger such as BQ, EDTA and IPA for trapping $\cdot \mathrm{O}^{2-}, \mathrm{h}^{+}$and $\cdot \mathrm{OH}$, respectively was added to the $\mathrm{RhB}$ solution containing T1 composite under visible light irradiation. The results are summarized in Fig. 4d. Experiments show that both BQ and EDTA suppress the RhB degradation and IPA has no apparent effects. This suggests that $\cdot \mathrm{O}^{2-}$ and $\mathrm{h}^{+}$are responsible for $\mathrm{RhB}$ degradation. Superoxide radicals are produced from the surface-adsorbed molecular oxygen after reacting with photogenerated electrons. It indicates forming and separation of photogenerated electrons and holes are crucial for the degradation of RhB. It is similar to that of single halide and binary halides doped bismuth terephthalate composites. ${ }^{31,32,40}$ Photodegradation of RhB itself is negligible in the absence of asprepared catalyst during the experimental process. The catalyst plays important role for RhB photodegradation. The result of UV-Vis-DRS reveals T1 is an UV light responsive catalyst. Photocatalytic degradation of RhB over T1 under visible light irradiation can only be explained through photosensitization process, colored RhB can be used as a photosensitizer under visible light irradiation, i.e., RhB absorbed on the surface of catalyst T1 was excited under visible light irradiation, its high energy electrons were transferred into the conduction band of the catalyst and then reacted with oxygen to produce superoxide radicals, which can decompose RhB. And holes also can participate in photodegradation reactions directly or indirectly to mineralize the pollutants. ${ }^{19,41}$

\section{Conclusions}

Five multiple halide anions doped bismuth terephthalate composites were prepared by doping three or four halide anions and keeping the molar ratios of $\mathrm{X}^{-} / \mathrm{Bi}^{3+}$ at 0.25 , i.e., $\mathrm{T} 1$ (containing $\mathrm{F}^{-}, \mathrm{Cl}^{-}, \mathrm{Br}^{-}$), $\mathrm{T} 2$ (containing $\mathrm{F}^{-}, \mathrm{Cl}^{-}, \mathrm{I}^{-}$), T3 (containing $\mathrm{F}^{-}, \mathrm{Br}^{-}, \mathrm{I}^{-}$), $\mathrm{T} 4$ (containing $\mathrm{Cl}^{-}, \mathrm{Br}^{-}, \mathrm{I}^{-}$) and $\mathrm{T} 5$ (containing $\mathrm{F}^{-}$, $\mathrm{Cl}^{-}, \mathrm{Br}^{-}, \mathrm{I}^{-}$). Their photodegradation activities were evaluated by degrading $\mathrm{RhB}$ under visible light irradiation and by degrading salicylic acid under UV light irradiation. Among all five composites, T1 and T5 exhibit excellent visible light degradation activities for RhB and UV light degradation activities for salicylic acid. T1 and T5 composites exhibit 41/35 times higher degradation activity on $\mathrm{RhB}$ and $7 / 6$ times higher degradation activity on salicylic acid than that of BiBDC. $\mathrm{F}^{-}$, $\mathrm{Cl}^{-}, \mathrm{Br}^{-}$anions codoped bismuth terephthalate (T1) exhibits 
excellent photocatalytic activities, while addition of iodide anions as the co-dopant little hindered these activities owing to the induced large charge-transfer resistance from the incorporation of iodide anions into bismuth terephthalate. The higher photodegradation efficiency of $\mathrm{T} 1$ and $\mathrm{T} 5$ was ascribed to regularly lamellar morphology, large specific BET surface area and efficient separation of photoelectron-hole pairs and charge transfer. Bismuth terephthalate was doped with multiple halide anions, providing the negative charges interacting with $\left[\mathrm{Bi}_{2} \mathrm{O}_{2}\right]$ sheets to enhance catalytic performance for pollutants removal.

\section{Conflicts of interest}

There are no conflicts to declare.

\section{Acknowledgements}

The work was supported by the National Natural Science Foundation of China (grant numbers 21273089, 21503282, 21571192), Project of Wuhan Science and Technology (2015070504020220), the Fundamental Research Funds for the Central Universities, South-Central University for Nationalities (CZP17004, CZZ17002).

\section{References}

1 A. Dhakshinamoorthy, A. M. Asiri and H. García, Angew. Chem., Int. Ed., 2016, 55(18), 5414-5445.

2 X.-M. Lin, J.-L. Niu, J. Lin, L.-M. Wei, L. Hu, G. Zhang and Y.-P. Cai, Inorg. Chem., 2016, 55(17), 8244-8247.

3 S. Maiti, A. Pramanik, U. Manju and S. Mahanty, ACS Appl. Mater. Interfaces, 2015, 7(30), 16357-16363.

4 M. Cheng, G. Zeng, D. Huang, C. Lai, P. Xu, C. Zhang, Y. Liu, J. Wan, X. Gong and Y. Zhu, J. Hazard. Mater., 2016, 312, 184191.

5 C. Zhou, C. Lai, D. Huang, G. Zeng, C. Zhang, M. Cheng, L. Hu, J. Wan, W. Xiong, M. Wen, X. Wen and L. Qin, Appl. Catal., B, 2018, 220, 202-210.

6 C. Zhou, C. Lai, P. Xu, G. Zeng, D. Huang, Z. Li, C. Zhang, M. Cheng, L. Hu, J. Wan, F. Chen, W. Xiong and R. Deng, ACS Sustainable Chem. Eng., 2018, 6(5), 6941-6949.

7 C. Zhou, C. Lai, P. Xu, G. Zeng, D. Huang, C. Zhang, M. Cheng, L. Hu, J. Wan, Y. Liu, W. Xiong, Y. Deng and M. Wen, ACS Sustainable Chem. Eng., 2018, 6(3), 4174-4184.

8 H. Yu, C. Cao, X. Wang and J. Yu, J. Phys. Chem. C, 2017, 121(24), 13191-13201.

9 Z.-F. Huang, J. Song, L. Pan, X. Jia, Z. Li, J.-J. Zou, X. Zhang and L. Wang, Nanoscale, 2014, 6(15), 8865-8872.

10 Z.-F. Huang, L. Pan, J.-J. Zou, X. Zhang and L. Wang, Nanoscale, 2014, 6(23), 14044-14063.

11 X. Wang, D. Liao, H. Yu and J. Yu, Dalton Trans., 2018, 47(18), 6370-6377.

12 X. Li, C. Zhu, Y. Song, D. Du and Y. Lin, RSC Adv., 2017, 7(17), 10235-10241.

13 B.-C. Xiao, L.-Y. Lin, J.-Y. Hong, H.-S. Lin and Y.-T. Song, RSC Adv., 2017, 7(13), 7547-7554.
14 Z. Zhang, M. Wang, W. Cui and H. Sui, RSC Adv., 2017, 7(14), 8167-8177.

15 L. Pan, T. Muhammad, L. Ma, Z.-F. Huang, S. Wang, L. Wang, J.-J. Zou and X. Zhang, Appl. Catal., B, 2016, 189, 181-191.

16 G. Wang, Q. Sun, Y. Liu, B. Huang, Y. Dai, X. Zhang and X. Qin, Chem.-Eur. J., 2015, 21(6), 2364-2367.

17 S.-M. Zhou, D.-K. Ma, P. Cai, W. Chen and S.-M. Huang, Mater. Res. Bull., 2014, 60, 64-71.

18 A. C. Wibowo, M. D. Smith and H.-C. zur Loye, CrystEngComm, 2011, 13(2), 426-429.

19 L. Ding, R. Wei, H. Chen, J. Hu and J. Li, Appl. Catal., B, 2015, 172-173, 91-99.

20 Y. Feng, L. Li, J. Li, J. Wang and L. Liu, J. Hazard. Mater., 2011, 192(2), 538-544.

21 C. Chang, L. Zhu, S. Wang, X. Chu and L. Yue, ACS Appl. Mater. Interfaces, 2014, 6(7), 5083-5093.

22 H. Cheng, B. Huang and Y. Dai, Nanoscale, 2014, 6(4), 20092026.

23 K. Zhang, D. Zhang, J. Liu, K. Ren, H. Luo, Y. Peng, G. Li and X. Yu, CrystEngComm, 2012, 14(2), 700-707.

24 S. Shenawi-Khalil, V. Uvarov, Y. Kritsman, E. Menes, I. Popov and Y. Sasson, Catal. Commun., 2011, 12(12), 1136-1141.

25 Y. Na, Y.-I. Kim, D. W. Cho, D. Pradhan and Y. Sohn, Mater. Sci. Semicond. Process., 2014, 27, 181-190.

26 Y.-Y. Liu, W.-J. Son, J.-B. Lu, B.-B. Huang, Y. Dai and M.-H. Whangbo, Chem.-Eur. J., 2011, 17(34), 9342-9349.

27 F. Dong, Y. Sun, M. Fu, Z. Wu and S. C. Lee, J. Hazard. Mater., 2012, 219-220, 26-34.

28 J. Li, Y. Yu and L. Zhang, Nanoscale, 2014, 6(15), 8473-8488.

29 X. Sun, Y. Zhang, C. Li, Z. Zhang, Z. Peng, H. Si, J. Zhang and Y. Li, J. Alloys Compd., 2015, 638, 254-260.

30 K.-L. Zhang, C.-M. Liu, F.-Q. Huang, C. Zheng and W.-D. Wang, Appl. Catal., B, 2006, 68(3-4), 125-129.

31 X. Zhao, X. Xiong, X. Chen, J. Hu and J. Li, Appl. Organomet. Chem., 2016, 30(5), 304-310.

32 X. Zhao, X. Chen and J. Hu, Microporous Mesoporous Mater., 2017, 244, 284-290.

33 X. Zhao, B. Qian, Y. Lu and W. Yuan, J. Cent. South Univ. Technol., Nat. Sci. (Chin. Ed.), 2016, 35(04), 12-16.

34 M. Stylidi, D. I. Kondarides and X. E. Verykios, Appl. Catal., B, 2004, 47(3), 189-201.

35 P. Ji, J. Zhang, F. Chen and M. Anpo, Appl. Catal., B, 2009, 85(3-4), 148-154.

36 B. Xu, Y. An, Y. Liu, B. Huang, X. Qin, X. Zhang, Y. Dai and M.-H. Whangbo, Chem. Commun., 2016, 52(92), 1350713510.

37 N. T. S. Phan, K. K. A. Le and T. D. Phan, Appl. Catal., A, 2010, 382(2), 246-253.

38 D. Zhang, M. Wen, B. Jiang, G. Li and J. C. Yu, J. Hazard. Mater., 2012, 211-212, 104-111.

39 G. Dong, K. Zhao and L. Zhang, Chem. Commun., 2012, 48(49), 6178-6180.

40 X. Zhao, L. Zhang, L. a. Meng, J. Zhang and M. Lan, J. Cent. South Univ. Technol., Nat. Sci. (Chin. Ed.), 2018, 37(3), 5-9.

41 C. Chen, W. Ma and J. Zhao, Chem. Soc. Rev., 2010, 39(11), 4206-4219. 